\title{
Impact of the COVID-19 pandemic on cardiovascular mortality and catherization activity during the lockdown in central Germany: an observational study
}

\author{
Holger M. Nef ${ }^{1,2} \cdot$ Albrecht Elsässer $^{3} \cdot$ Helge Möllmann $^{4} \cdot$ Mohammed Abdel-Hadi $^{5} \cdot$ Timm Bauer $^{6} \cdot$ Martin Brück $^{7}$. \\ Holger Eggebrecht ${ }^{8}$. Joachim R. Ehrlich ${ }^{9} \cdot$ Markus W. Ferrari $^{10}$. Stephan Fichtlscherer ${ }^{2}$. Ulrich Hink ${ }^{11}$. \\ Hans Hölschermann ${ }^{12} \cdot$ Rifat Kacapor ${ }^{13}$. Oliver Koeth ${ }^{14}$. Serguei Korboukov ${ }^{15}$. Steffen Lamparter ${ }^{16}$. \\ Alexander J. Laspoulas ${ }^{1}$. Ralf Lehmann ${ }^{17}$. Christoph Liebetrau ${ }^{18}$. Tobias Plücker ${ }^{19}$. Jörn Pons-Kühnemann ${ }^{20}$. \\ Volker Schächinger ${ }^{21}$ - Bernhard Schieffer ${ }^{22}$ - Peter Schott ${ }^{23}$ - Matthias Schulze ${ }^{24}$. Claudius Teupe ${ }^{25}$. \\ Mariuca Vasa-Nicotera ${ }^{26} \cdot$ Michael Weber $^{27} \cdot$ Christoph Weinbrenner $^{28} \cdot$ Gerald Werner $^{29} \cdot$ Christian W. Hamm $^{1,18}$. \\ Oliver Dörr ${ }^{1} \cdot$ for the CoVCAD -Study Group
}

Received: 21 September 2020 / Accepted: 2 November 2020 / Published online: 21 November 2020

(c) The Author(s) 2020

\begin{abstract}
Aims During the COVID-19 pandemic, hospital admissions for cardiac care have declined. However, effects on mortality are unclear. Thus, we sought to evaluate the impact of the lockdown period in central Germany on overall and cardiovascular deaths. Simultaneously we looked at catheterization activities in the same region.

Methods and results Data from 22 of 24 public health-authorities in central Germany were aggregated during the pandemic related lockdown period and compared to the same time period in 2019. Information on the total number of deaths and causes of death, including cardiovascular mortality, were collected. Additionally, we compared rates of hospitalization $(n=5178)$
\end{abstract}

This article is not under consideration for publishing elsewhere and none of its content have been previously published; all authors have read and approved the final version of the manuscript.

\section{Holger M. Nef}

holger.nef@innere.med.uni-giessen.de

1 Department of Cardiology, Justus Liebig University Giessen, University Hospital Giessen, Medical Clinic I, Klinikstrasse 33, 35392 Giessen, Germany

2 Department of Cardiology, Herz-Kreislauf-Zentrum Klinikum Hersfeld-Rotenburg, Rotenburg, Germany

3 Department of Cardiology, Klinikum Oldenburg, Oldenburg, Germany

4 St.-Johannes-Hospital Klinik Für Innere Medizin I, Dortmund, Germany

5 Department of Cardiology, DRK Kliniken Nordhessen, Kassel, Germany

6 Department of Cardiology, Sana Klinikum Offenbach, Offenbach, Germany

7 Department of Cardiology, Lahn-Dill-Kliniken, Klinikum Wetzlar, Wetzlar, Germany

8 Department of Cardiology, Agaplesion Frankfurter Diakonie Kliniken, Frankfurt, Germany
9 Department of Cardiology, St. Josefs-Hospital Wiesbaden, Wiesbaden, Germany

10 Department of Cardiology, Helios Dr. Horst Schmidt Kliniken, Wiesbaden, Germany

11 Department of Cardiology, Klinikum Frankfurt Höchst, Frankfurt am Main, Germany

12 Department of Cardiology, Hochtaunus-Kliniken, Bad Homburg, Germany

13 Department of Cardiology, Kliniken Des Main-Taunus-Kreises, Bad Soden am Taunus, Germany

14 Department of Cardiology, GPR Gesundheits- Und Pflegezentrum Rüsselsheim, Rüsselsheim, Germany

15 Hessenklinik Stadtkrankenhaus Korbach, Korbach, Germany

16 Department of Cardiology, Diakonie-Krankenhaus Wehrda, Marburg, Germany

17 Department of Cardiology, Asklepios Kliniken Langen, Langen, Germany

18 Department of Cardiology, Kerckhoff Heart Center, Bad Nauheim, Germany

19 Department of Cardiology, Eichhof-Stiftung Lauterbach, Lauterbach, Germany 
for chronic coronary syndrome (CCS), acute coronary syndrome (ACS), and out of hospital cardiac arrest (OHCA) in 26 hospitals in this area. Data on 5,984 deaths occurring between March 23, 2020 and April 26, 2020 were evaluated. In comparison to the reference non-pandemic period in 2019 (deaths: $n=5832$ ), there was a non-significant increase in all-cause mortality of $2.6 \%$ [incidence rate ratio (IRR) $1.03,95 \%$ confidence interval (CI) 0.99-1.06; $p=0.16$ ]. Cardiovascular and cardiac mortality increased significantly by $7.6 \%$ (IRR $1.08,95 \%$-CI $1.01-1.14 ; p=0.02$ ) and by $11.8 \%$ (IRR $1.12,95 \%$-CI $1.05-1.19 ; p<0.001)$, respectively. During the same period, our data revealed a drop in cardiac catherization procedures.

Conclusion During the COVID-19-related lockdown a significant increase in cardiovascular mortality was observed in central Germany, whereas catherization activities were reduced. The mechanisms underlying both of these observations should be investigated further in order to better understand the effects of a pandemic-related lockdown and social-distancing restrictions on cardiovascular care and mortality.

\section{Graphic abstract}

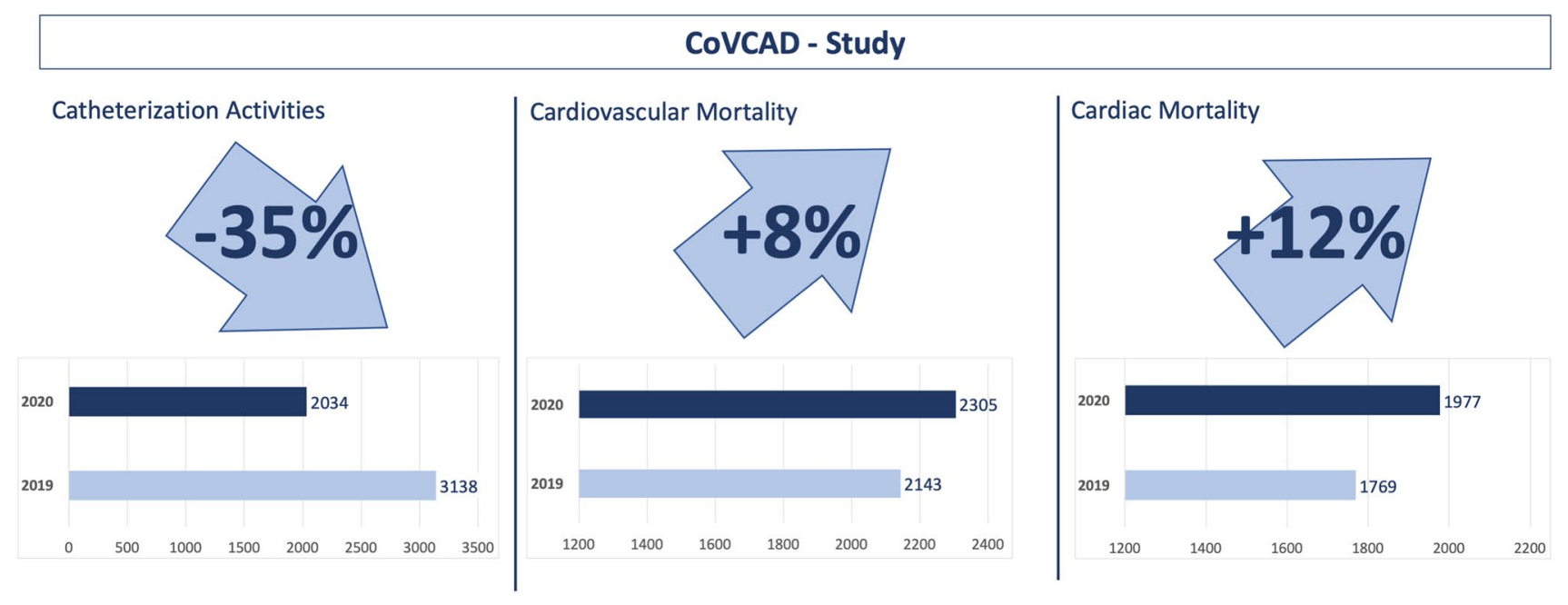

Keywords SARS-CoV2 pandemic $\cdot$ COVID-19 Chronic coronary syndrome $\cdot$ Acute coronary syndrome $\cdot$ Cardiovascular mortality

\section{Introduction}

The emergence of the COVID-19 pandemic has affected different spaces in the medical community [1-3]. Countries across Europe have significantly curbed public life in order to halt the spread of the COVID-19 outbreak $[1,2,4]$.

20 Justus Liebig University Giessen, Medical Statistics, Institute of Medical Informatics, Giessen, Germany

21 Department of Cardiology, Klinikum Fulda, Fulda, Germany

22 Department of Internal Medicine/Cardiology and Angiology, University Hospital of Marburg, Marburg, Germany

23 Department of Cardiology, Klinikum Werra Meissner $\mathrm{GmbH}$, Eschwege, Germany

24 Department of Cardiology, Asklepios Schwalm-Eder-Kliniken, Schwalmstadt, Germany

25 Department of Cardiology, Krankenhaus Sachsenhausen, Frankfurt am Main, Germany
In central Germany, the State of Hesse issued a lockdown from March 23rd until April 26th, 2020, ordering approximately 6 million residents to "stay at home". The official government guidelines stated that people should go shopping "as infrequently as possible", and leave their homes only for "essentials". Schools, universities, and all non-essential
26 Department of Cardiology, University of Frankfurt, Frankfurt, Germany

27 Department of Cardiology, Kreisklinik Groß-Umstadt, Groß-Umstadt, Germany

28 Department of Cardiology, Klinikum Hanau, Hanau, Germany

29 Department of Cardiology, Klinikum Darmstadt, Darmstadt, Germany 
businesses were closed. Travel within Germany was banned except for health reasons or urgent matters. From several reports coming from US and Europe, it is well known that the epidemiological crisis and the following lockdown period has strongly impacted cardiac care. Analyses demonstrated that in the pandemic the number of visits to ambulatory care practices declined by nearly $60 \%$ [5]. Moreover, there was a clear impact of the COVID-19 pandemic on heart failure hospitalization and management [6]. Additionally, the incidence of hospitalization for patients with acute coronary syndromes (ACS) showed a dramatic drop of approximately $40 \%$ and was even more pronounced in patients with chronic coronary syndrome with an unknown effect on cardiovascular mortality [7-11].

Against this background, the aim of the present observational CoVCAD (COVid-19 and CArdiovascular Disease) study was to systematically analyze cardiovascular mortality including ACS, heart failure, heart rhythm disorders (summarized as cardiac death), pulmonary embolism, and stroke in central Germany during the lockdown-related "stay at home" reaction in comparison to the same non-pandemic period in 2019 and to investigate changes in numbers of catheterization for cardiac catheterization.

\section{Methods}

\section{Study design and data acquisition}

In a comprehensive analysis, mortality data from local public health authorities in central Germany (Hesse) were aggregated from March 23rd to April 26th, 2020. A total of 22 out of $24(92 \%)$ health authorities from this region participated in the present CoVCAD study. The data were compared to a reference non-pandemic period in 2019 from the same health authorities nationwide for the region of central Germany to ensure a direct comparison between the periods. In addition, information on all-cause mortality and causes of death was gathered by reviewing all available death certificates. Causes of death were documented by a physician at the last medical contact who signed the death certificate, including in-hospital deaths as well as out-of-hospital deaths.

Thereby, we focused on cardiovascular mortality including ACS, heart failure, heart rhythm disorders (summarized as cardiac death), pulmonary embolism, and stroke. Additionally, we assessed mortality resulting from other causes that were summarized as non-cardiovascular death as well as all non-COVID-19 death.

COVID-19 death was documented when the patients were tested positive, irrespective of other comorbidities. During the lockdown, all patients who were admitted to a hospital were tested for COVID-19 if the following criteria of the Robert-Koch-Institute were fulfilled: (1) typical respiratory symptoms, (2) contact with a person who tested positive during the past 14 days, or (3) stay at a region of risk during the past 14 days.

For the analysis of catherization activities, hospitals in central Germany were asked to provide data for all patients who were admitted for cardiac catheterization due to chronic coronary syndromes (CCS), ACS (NSTE-ACS, STEMI), and out-of-hospital cardiopulmonary arrest (OHCA) during the lockdown period from March 23rd to April 26th, 2020. In addition, data were acquired retrospectively from March 23rd to April 26th, 2019 from these catheterization laboratories. A total of 26 hospitals contributed to the present study. Data assessment and participation in the CoVCAD study were optional. For further analysis, patients' characteristics and procedural data were assessed from the participating hospitals. To exclude variations for catherization activities for other reasons (recent studies, e.g. ISCHEMIA trial; improved primary or secondary prevention) we also analyzed catheter laboratory volumes from January to February 2020 compared with January to February 2019, defined as an immediately adjacent non-pandemic period.

The study protocol was approved by the ethics committee of the medical faculty of the Justus-Liebig-University of Giessen, Germany (AZ 60/20). The investigation conforms to the principles outlined in the Declaration of Helsinki. The statistical analysis was performed by the department of medical statistics at the University of Giessen, Germany.

\section{Statistical analysis}

Categorical variables are reported as numbers and percentages. Comparisons of categorical variables were executed by Pearson $\chi 2$-test without continuity correction. Confidence Intervals of relative change of numbers were estimated by Poisson Regression. Continuous variables were evaluated by QQ-Plot and Shapiro-Wilk-Test for normal distribution. As normal distribution was rejected, continuous variables are expressed as median with interquartile range and comparisons were executed by Mann-Whitney test. Incidence rates (Daily Events) were calculated by dividing the number of cumulative admissions by the number of days for each time period ( 35 days). Incidence rate ratios comparing the 2020 study period with the control period (2019) were estimated by Poisson regression analysis including year as explanation factor and center as confounder. No adjustments for multiple testing were performed. For all statistical analyses, the statistical software R-4.0.0 (R Core Team 2020) was used. 
Table 1 Mortality data during the lockdown period in 2020 in comparison to the non-pandemic period in 2019

\begin{tabular}{|c|c|c|c|c|c|c|c|}
\hline & Events 2019 & Events 2020 & $\begin{array}{l}\text { Delta Events } \\
2019 \text { vs. } 2020\end{array}$ & Daily Events 2019 & Daily Events 2020 & $\begin{array}{l}\text { Incidence rate } \\
\text { ratio }(95 \% \mathrm{CI})\end{array}$ & $P$-value \\
\hline All-cause mortality & 5832 & 5984 & 152 & 166.63 & 170.97 & $1.03(0.99-1.06)$ & 0.16 \\
\hline Cardiovascular mortality & 2143 & 2305 & 162 & 61.23 & 65.86 & $1.08(1.01-1.14)$ & 0.02 \\
\hline Cardiac mortality & 1769 & 1977 & 208 & 50.54 & 56.49 & $1.12(1.05-1.19)$ & 0.001 \\
\hline Stroke & 270 & 213 & -57 & 7.71 & 6.09 & $0.79(0.66-0.94)$ & 0.01 \\
\hline Pulmonary embolism & 104 & 115 & 11 & 2.97 & 3.29 & $1.11(0.85-1.44)$ & 0.46 \\
\hline COVID death & - & 320 & 320 & - & 9.14 & $-\#$ & - \\
\hline Other & 3689 & 3359 & -330 & 105.40 & 95.97 & $0.91(0.87-0.95)$ & 0.001 \\
\hline
\end{tabular}

\#Incidence rate ratio not estimable

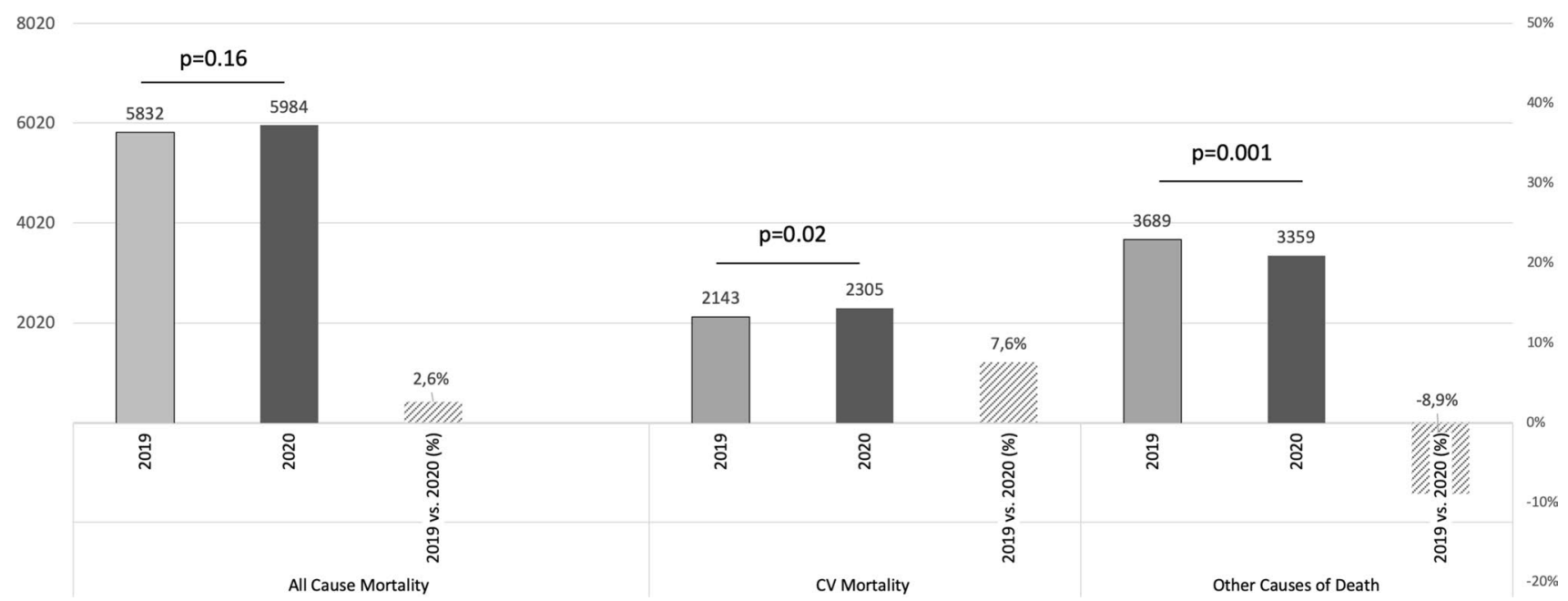

Fig. 1 All-cause mortality, cardiovascular mortality, and other causes of death during the lockdown period in 2020 in comparison to the nonpandemic period in 2019

\section{Results}

\section{Mortality during the pandemic-related lockdown}

From March 23rd to April 26th, 2020, a total of 5984 deaths were registered by the participating public health authorities in central Germany (Hesse) during the analyzed lockdown period. In comparison, during the similar non-pandemic period in 2019 , the number of deaths was 5,832, resulting in a non-significant increase in all-cause mortality by $2.6 \%$ [incidence rate ratio (IRR) 1.03, 95\% confidence interval (CI) $0.99-1.03 ; p=0.02$ ]. This was mainly driven by the absolute number of deaths resulting from COVID-19 ( $n=320$, Table 1; Figs. 1 and 2).

During the lockdown period, there was an increase in cardiovascular mortality, comprising cardiac death, pulmonary embolism, and stroke, of 7.6\% (IRR 1.08, 95\% CI 1.01-1.14; $p=0.02$ ) (Fig. 1). Cardiac mortality increased by $11.8 \%$
(IRR 1.12, 95\% CI 1.05-1.19; $p<0.001$ ). The incidence of fatal pulmonary embolism increased by $10.6 \%$ (IRR 1.11 , 95\% CI $0.85-1.44 ; p<0.46)$, although this change was without any statistical significance. In contrast, the number of patients who deceased due to stroke (IRR $0.79,95 \%$ CI $0.66-0.94 ; p=0.01$ ) and other causes of death (IRR 0.91 , 95\% CI 0.87-0.95; $p=0.001)$ was lower during the lockdown period in 2020 (Table 1).

\section{Evaluation of cardiac catherization activities}

In the final analysis, 5579 patients from 26 hospitals in central Germany (Hesse) were enrolled in the CoVCAD study. The participating hospitals were representative of all hospitals in central Germany, given the fact that there was a balanced proportion of patients enrolled either in university hospitals/heart centers $(n=2812)$ or in district hospitals $(n=2767)$. In addition, the duration of hospital 
stay did not differ between university hospitals/heart centers (6.7 days) and district hospitals (5.48 days). During the lockdown period from March 23rd to April 26th, 2020, a total of 2034 patients were admitted for cardiac catheterization to the participating hospitals. Out of these patients, 1112 (55\%) presented with CCS, 560 (28\%) with NSTEACS, $300(15 \%)$ with STEMI, and 58 (3\%) with OHCA. During the same non-pandemic period in 2019, a total of 3138 patients were admitted, including 2008 (64\%) with CCS, 750 (24\%) with NSTE-ACS, 311 (10\%) with STEMI, and $69(2 \%)$ with OHCA (Table 2).

When comparing the lockdown period 2020 with the reference non-pandemic period in 2019, we found a $44.6 \%$ (2008 vs. 1112) decrease in the number of elective procedures, and a drop of $18.9 \%$ (1061 vs. 860) in ACS-related procedures was documented. The number of patients was reduced by $25.3 \%$ for NSTE-ACS (750 vs. 560 ) and by $3.5 \%$ for STEMI (320 vs. 311) (Table 2). All patient characteristics analyzed are presented in Table 3.

Overall, the total number of percutaneous coronary interventions (PCI) was lower in the lockdown period in comparison to the non-pandemic period, although the difference in the relative number of PCI procedures was not statistically significant (Table 2). The relative number of complex PCI procedures also did not differ (CTO: $p=0.153$, bifurcation: $p=0.774$, left main: $p=0.516$ ). Specific procedural characteristics are presented in Table 2. Catherization activities from the high-volume centers in central Germany showed a declining, but not significant, trend during the immediately adjacent pre-pandemic (January-February 2020) period when compared with 2019 (1958 vs. 1859).

During the COVID-19 pandemic, in-hospital mortality in patients admitted for cardiac catherization was higher when compared with 2019 (58/1,801 vs. 55/3,030, $p=0.002)$. However, the length of hospital stay $(6.2 \pm 5.9$ days vs. $6.7 \pm 7.8$ days; $p=0.657$ ) did not differ when comparing the two periods.

\section{Discussion}

COVID-19 pandemic has placed an enormous strain on the healthcare systems worldwide, with dramatic implications for medical practice $[4,12,13]$. The present pandemic has led to modifications of standard practice in cardiac care, including for patients presenting with acute coronary syndromes [14-16].

Recent data from the USA, China, Spain, and Italy, and also preliminary data from Germany have provided information that the COVID-19 pandemic period has led to a significant reduction in the number of procedures being carried out in interventional cardiology $[9,17-19]$.
Accordingly, coronary catherization in patients with ACS declined by approximately $40 \%$, and this decline was even more pronounced in patients with CCS $[15,18]$. In addition, management of PCI in patients with NSTE-ACS and STEMI was more challenging due to delays in transfer times, prolonged emergency department evaluations, and infection control requirements in catherization laboratories that resulted in delays in treatment [9].

In the central German State of Hesse, with a population of approximately 6 million, the rate of all-cause mortality increased during the COVID-19-related lockdown compared with the same reference period in 2019. More important, the proportion of cardiovascular deaths increased by $7.6 \%$. In accordance with recent reports, in the present study the number of patients with CCS, NSTE-ACS, and STEMI who were admitted to medical departments for cardiac catherization was lower during the lockdown period in 2020 than in the same non-pandemic period in 2019 [7, 9, 15, 17-19]. Given the potentially heightened environmental and psychosocial stressors and the fact that COVID-19 infections may induce acute cardiac injury or myopericarditis mimicking ACS, at least an increase in patients with ACS could have been expected $[2-4,13]$.

Potential reasons for the deferrals of these patients during the pandemic are different: First, there is a particular patient-based anxiety to come to the hospital due to COVID19. This behavior was potentially reinforced by the official governments order to "stay at home". Second, exhausted outpatient care capacities during lockdown might further delay cardiac care. Third, the triage of patients according to priority levels, with patients with assumed elective procedures being put on a waiting list, has kept patients from urgently seeking medical attention for chest pain [9].

When comparing in-hospital mortality in patients admitted for cardiac catheterization there was an increase in 2020 indicating that these patients were potentially referred too late to the hospital. This finding is in line with several reports in the literature demonstrating complications after myocardial infarction more frequently due to delayed presentation [20]. It has to be concluded that the fear of contracting COVID-19, although justified, here may have resulted in an increase in non-COVID morbidity and mortality caused by avoidance of the medical system.

In contrast to the higher rate of cardiovascular deaths, the rate of mortality following stroke decreased during the lockdown period. This finding is may potentially be explained by misdiagnosed or underdiagnosed stroke during lockdown. Accordingly, Rinkel et al. observed a $24 \%$ decrease in suspected stroke presentation during the lockdown period in the Netherlands [23]. The decrease in numbers of death due to other reasons during the lockdown period in 2020 compared with the non-pandemic period in 2019 might be explained 


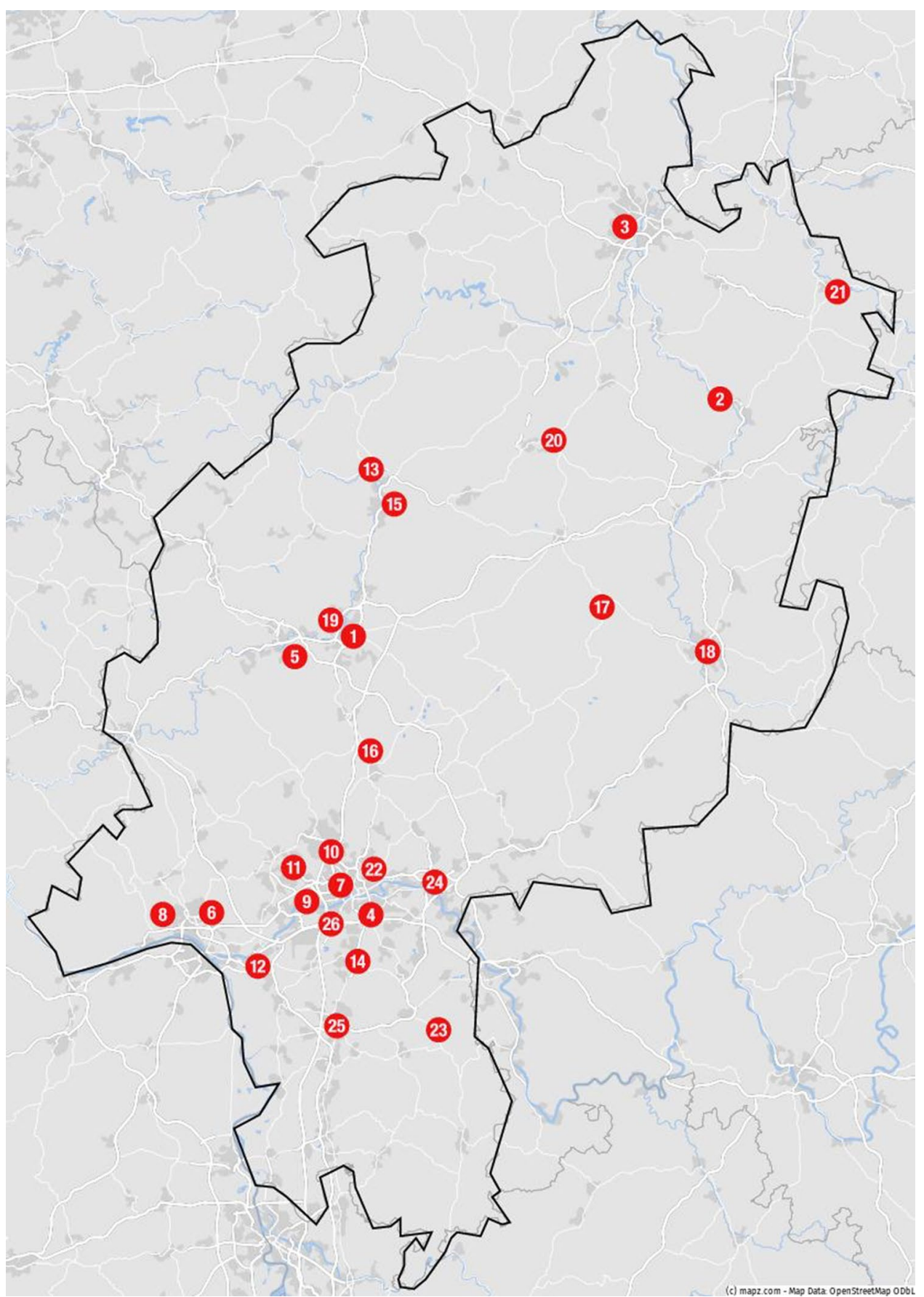

by the fact that during the lockdown period there were fewer traffic accidents [24] and less crime [25].

Catheterization activities from the high-volume centers in central Germany were similar in the pre-pandemic when compared to 2019 excluding any influence of recently published studies (e.g. ISCHEMIA Trial) regarding the optimal indication for coronary angiography. However, in the present study, possible changes in local protocols of ACS patient management during the COVID-19 pandemic were not assessed. Since the proportion of complex cardiac catherization procedures did not increase during the pandemic-related lockdown, a balanced and appropriate prioritization of elective procedures in the hospitals can be assumed. Most importantly, the adequate care of STEMI patients in line with the guidelines was maintained despite potential locally limited resources, as evidenced by similar door-to-balloon times.

An inherent limitation of the present study is the lack of an autopsy-based diagnosis confirming the definite cause of death. Causes of death were documented by a physician at 
4Fig. 2 Map of the state of Hesse, including all participating hospitals to the CoVCAD-Study: (1) Justus Liebig University Giessen, University Hospital Giessen, Medical Clinic I, Giessen (2) HerzKreislauf-Zentrum Klinikum Hersfeld-Rotenburg, Dept. of Cardiology, Rotenburg (3) Hessenklinik Stadtkrankenhaus Korbach, Korbach (4) Sana Klinikum Offenbach, Dept. of Cardiology, Offenbach (5) Lahn-Dill-Kliniken, Klinikum Wetzlar, Dept. of Cardiology, Wetzlar (6) St. Josefs-Hospital Wiesbaden, Dept. of Cardiology, Wiesbaden (7) Agaplesion Frankfurter Diakonie Kliniken, Dept. of Cardiology, Frankfurt (8) Helios Dr. Horst Schmidt Kliniken, Dept. of Cardiology, Wiesbaden (9) Klinikum Frankfurt Höchst, Dept. of Cardiology, Frankfurt am Main (10) Hochtaunus-Kliniken, Bad Homburg, Dept. of Cardiology (11) Kliniken des Main-Taunus-Kreises, Dept. of Cardiology (12) GPR Gesundheits- und Pflegezentrum Rüsselsheim, Dept. of Cardiology, Rüsselsheim (13) Diakonie-Krankenhaus Wehrda, Dept. of Cardiology, Marburg (14) Asklepios Kliniken Langen, Dept. of Cardiology, Langen (15) Department of Internal Medicine/Cardiology and Angiology, University Hospital of Marburg, Marburg (16) Kerckhoff Heart Center, Dept. Of Cardiology, Bad Nauheim (17) Eichhof-Stiftung Lauterbach, Dept. of Cardiology (18) Klinikum Fulda, Dept. of Cardiology, Fulda (19) Agaplesion Evangelisches Krankenhaus Mittelhessen, Dept. of Cardiology Giessen (20) Asklepios Schwalm-Eder-Kliniken, Dept. of Cardiology, Schwalmstadt (21) Klinikum Werra Meissner GmbH, Dept. of Cardiology, Eschwege (22) Krankenhaus Sachsenhausen, Dept. of Cardiology, Frankfurt am Main (23) Kreisklinik Groß-Umstadt, Dept. of Cardiology, Groß-Umstadt (24) Klinikum Hanau, Dept. of Cardiology, Hanau (25) Klinikum Darmstadt, Dept. of Cardiology, Darmstadt (26) University of Frankfurt, Dept. of Cardiology, Frankfurt

the last medical contact. This could mean that an existing COVID-19 diagnosis wrongly failed to state other causes of death. Moreover, COVID-19 infections could also have been overlooked due to the fact that thromboembolic or atherothrombotic events leading to death and listed as the cause of death, e. g. myocardial infarction, could be at least partially related to an existing non-diagnosed COVID-19 infection. Nevertheless, this was performed consistently during the pandemic period as well as during the non-pandemic period in 2019. In the present study the proportion of patients who died in hospital or out of hospital was not assessed. Given this fact, unrecognized/undiagnosed COVID-19 deaths have to be considered. However, due to the extensive testing for COVID-19 in central Germany during the lockdown period we assume a negligible number of misdiagnosed patients; conversely, cases of sudden cardiac death may have been attributed erroneously to COVID-19. According to recently published data, stent thrombosis occurred significantly more frequently in patients with COVID-19 infections [26]. Additionally, a German COVID-19 autopsy study revealed a remarkable rate of deaths (5\%) finally defined as nonCOVID 19 deaths with virus-independent causes (e.g. pulmonary embolism or myocardial infarction).

A further potential limitation is that only patients who were admitted for cardiac catheterizations were included in the present study. Thus, admissions for other cardiovascular reasons (e.g. heart failure, arrhythmias, pulmonary embolism) during the pandemic-related lockdown were not assessed. However, it must be assumed that hospitalization for other cardiovascular reasons also declined,; e.g. Bromage et al. showed a significant decrease in acute heart failure admissions [6].

In summary, the common recommendation to defer elective cardiac procedures during the lockdown phase of the COVID-19 pandemic of 2020 in order to preserve resources (including personal protective equipment and hospital beds) led to a restrictive attitude in the use of the highly developed
Table 2 Clinical presentation of patients who were admitted for cardiac catheterization during the pandemic-related lockdown period and non-pandemic period

\begin{tabular}{lllll}
\hline Clinical presentation & 2019 & 2020 & Change $\%\left(95 \%\right.$ CI $^{1}$ & $p$ value $^{1}$ \\
\hline CCS, $n$ & 2008 & 1112 & $44.6(40.4-48.5)$ & $<0.001$ \\
ACS, $n$ & 1061 & 860 & $18.9(11.3-25.9)$ & $<0.001$ \\
NSTE-ACS, $n$ & 750 & 560 & $25.3(16.7-33.1)$ & $<0.001$ \\
STEMI, $n$ & 311 & 300 & $3.5(0-17.7)$ & 0.656 \\
OHCA, $n$ & 69 & 58 & $15.9(0-40.7)$ & 0.330 \\
Procedural characteristics & 2019 & 2020 & & $p$-value ${ }^{2}$ \\
PCI, $n(\%)$ & $1173 / 2084(56)$ & $687 / 1290(53)$ & & 0.163 \\
LM PCI, $n(\%)$ & $91 / 1725(5)$ & $51 / 1080(5)$ & & 0.516 \\
CTO-PCI, $n(\%)$ & $67 / 1727(4)$ & $54 / 1079(5)$ & & 0.153 \\
Bifurcation-PCI, $n$ (\%) & $79 / 1724(5)$ & $47 / 1080(4)$ & & 0.774 \\
Door to balloon Time & $36(25-52.5)$ & $34(25-59.8)$ & & $0.783^{3}$ \\
$\quad$ STEMI), median (IQR) & & & & \\
\hline
\end{tabular}

Tests used: ${ }^{1}$ Poisson regression; ${ }^{2}$ Pearson $\mathrm{X}^{2}$ test; ${ }^{3}$ Wilcoxon test

ACS acute coronary syndrome, CCS Chronic coronary syndrome, LM: left main, NSTE-ACS acute coronary syndrome without ST-elevation, $O H C A$ out-of-hospital cardiac arrest, $P C I$ percutaneous coronary intervention, STEMI ST-elevation myocardial infarction 
Table 3 Demographics of patients undergoing cardiac catherization

\begin{tabular}{llll}
\hline Demographics & 2019 & 2020 & $P$-value \\
\hline & $N=3545$ & $N=2034$ & \\
Male, $n(\%)$ & $1852 / 2826(66)$ & $1105 / 1604(69)$ & $0.023^{1}$ \\
Age, median (IQR) & $70(60-79)$ & $70(59-78)$ & $0.052^{2}$ \\
History of CAD, $n(\%)$ & $940 / 2034(46)$ & $555 / 1178(47)$ & $0.622^{1}$ \\
Diabetes mellitus, n (\%) & $588 / 1923(31)$ & $341 / 1212(28)$ & $0.145^{1}$ \\
Hypertension, $n(\%)$ & $1391 / 1769(79)$ & $891 / 1111(80)$ & $0.313^{1}$ \\
Currently smoking, $n$ & $325 / 1641(20)$ & $254 / 1102(23)$ & $0.041^{1}$ \\
$\quad(\%)$ & & & \\
Chronic kidney disease, & $347 / 1766(20)$ & $217 / 1106(20)$ & $0.985^{1}$ \\
$\quad n(\%)$ & & & \\
BMI, median (IQR) & $27(24.6-31)$ & $27.2(24.2-30.5)$ & $0.321^{2}$ \\
LV function, median & $55(45-60)$ & $55(45-60)$ & $0.188^{2}$ \\
$\quad$ IQR) & & & \\
ACE-I / ARB, $n(\%)$ & $1124 / 1740(65)$ & $753 / 1089(69)$ & $0.013^{1}$ \\
B-Blocker, $n(\%)$ & $1031 / 1740(59)$ & $700 / 1089(64)$ & $0.008^{1}$ \\
Diuretics, $n(\%)$ & $726 / 1739(42)$ & $435 / 1089(40)$ & $0.343^{1}$ \\
\hline
\end{tabular}

Tests used: ${ }^{1}$ Pearson $\chi^{2}$-test; ${ }^{2}$ Wilcoxon test

healthcare system in central Germany. This consequently led to reduced admissions for elective cardiac catherization and, even more critically, to a reduction of referrals for ACS.

It can only be speculated whether this restricted healthcare affected the observed increase in cardiovascular and cardiac mortality during the COVID-19 pandemic-related lockdown and the associated social distancing restrictions; however, national programs should be designed to counteract the fact that under such conditions patients at higher cardiovascular risk hesitate to seek cardiac care when symptoms occur. The data emphasize the importance of maintaining low-threshold access to cardiovascular care during such a pandemic.

Acknowledgements Collaborators: Abdulaziz Al-Hariri: Kliniken des Main-Taunus-Kreises, Department of Cardiology, Germany, Ursula Boening: Department of Cardiology, Justus Liebig University Giessen, University Hospital Giessen, Medical Clinic I, Klinikstrasse 33, 35392 Giessen, Germany, Sven Faßbender: University of Frankfurt, Department of Cardiology, Frankfurt, Germany, Charlotte Funk: Department of Cardiology, Justus Liebig University Giessen, University Hospital Giessen, Medical Clinic I, Klinikstrasse 33, 35392 Giessen, Germany, Moritz Haas: Kerckhoff Heart Center, Department of Cardiology, Bad Nauheim, Germany, Catharina Hamm: Kerckhoff Heart Center, Department of Cardiology, Bad Nauheim, Germany, Felix Hofmann: Department of Cardiology, Justus Liebig University Giessen, University Hospital Giessen, Medical Clinic I, Klinikstrasse 33, 35392 Giessen, Germany, Konstantinos Karatolios: Department of Internal Medicine/Cardiology and Angiology, University Hospital of Marburg, Marburg Germany, Tore Körschgen: Kerckhoff Heart Center, Department of Cardiology, Bad Nauheim, Germany, Kerstin Michalek: Klinikum Frankfurt Höchst, Department of Cardiology, Frankfurt am Main, Germany, Shari Schauberger: Herz-Kreislauf-Zentrum Klinikum Hersfeld-Rotenburg, Department of Cardiology, Rotenburg, Germany, Sylvana Neumann: Department of Cardiology, Justus Liebig University
Giessen, University Hospital Giessen, Medical Clinic I, Klinikstrasse 33, 35392 Giessen, Germany, Thorsten Runde: Lahn-Dill-Kliniken, Klinikum Wetzlar, Dept. of Cardiology, Wetzlar, Germany, Wiebke Rutsatz: Department of Cardiology, Justus Liebig University Giessen, University Hospital Giessen, Medical Clinic I, Klinikstrasse 33, 35392 Giessen, Germany, Michael Stanisch: Klinikum Hanau, Department of Cardiology, Hanau Germany, Peter Schifferings: Hochtaunus-Kliniken, Bad Homburg, Department of Cardiology, Germany, Eberhard Schneider: GPR Gesundheits- und Pflegezentrum Rüsselsheim, Department of Cardiology, Rüsselsheim, Germany, Maren Weferling: Kerckhoff Heart Center, Department of Cardiology, Bad Nauheim, Germany. The authors thank Elizabeth Martinson, $\mathrm{PhD}$, for editorial assistance.

Funding Open Access funding enabled and organized by Projekt DEAL.

\section{Data availability Yes.}

\section{Compliance with ethical standards}

Conflicts of interest The authors have no conflicts of interest to declare. Holger M. Nef and Christian W. Hamm are principal investigators of the DZHK (German Center for Cardiovascular Research).

Ethics approval The study protocol was approved by the ethics committee of the medical faculty of the Justus-Liebig-University of Giessen, Germany (AZ 60/20). The investigation conforms to the principles outlined in the Declaration of Helsinki. The statistical analysis was performed by the department of medical statistics at the University of Giessen, Germany.

Consent for publication All authors have read the present manuscript and approved the submission to Clinical Research in Cardiology.

Open Access This article is licensed under a Creative Commons Attribution 4.0 International License, which permits use, sharing, adaptation, distribution and reproduction in any medium or format, as long as you give appropriate credit to the original author(s) and the source, provide a link to the Creative Commons licence, and indicate if changes were made. The images or other third party material in this article are included in the article's Creative Commons licence, unless indicated otherwise in a credit line to the material. If material is not included in the article's Creative Commons licence and your intended use is not permitted by statutory regulation or exceeds the permitted use, you will need to obtain permission directly from the copyright holder. To view a copy of this licence, visit http://creativecommons.org/licenses/by/4.0/.

\section{References}

1. Grasselli G, Pesenti A, Cecconi M (2020) Critical care utilization for the COVID-19 outbreak in Lombardy, Italy: early experience and forecast during an emergency response. JAMA. https://doi. org/10.1001/jama.2020.4031

2. Saglietto A, D’Ascenzo F, Zoccai GB, De Ferrari GM (2020) COVID-19 in Europe: the Italian lesson. Lancet 395(10230):1110 1111. https://doi.org/10.1016/S0140-6736(20)30690-5

3. Rosenbaum L (2020) The Untold Toll - The Pandemic's Effects on Patients without Covid-19. N Engl J Med. https://doi.org/10.1056/ NEJMms 2009984 
4. Gori T, Lelieveld J, Munzel T (2020) Perspective: cardiovascular disease and the Covid-19 pandemic. Basic Res Cardiol 115(3):32. https://doi.org/10.1007/s00395-020-0792-4

5. Ateev Mehrotra MC, David Linetsky, Hilary Hatch, David Cutler (2020) The Impact of the COVID-19 Pandemic on Outpatient Visits. Commonwealth Fund https://doi.org/10.26099/ ds9e-jm36

6. Bromage DI, Cannata A, Rind IA, Gregorio C, Piper S, Shah AM, McDonagh TA (2020) The impact of COVID-19 on heart failure hospitalization and management: report from a Heart Failure Unit in London during the peak of the pandemic. Eur J Heart Fail 22(6):978-984. https://doi.org/10.1002/ejhf.1925

7. De Rosa S, Spaccarotella C, Basso C, Calabro MP, Curcio A, Filardi PP, Mancone M, Mercuro G, Muscoli S, Nodari S, Pedrinelli R, Sinagra G, Indolfi C, Societa Italiana C, the CCUAig (2020) Reduction of hospitalizations for myocardial infarction in Italy in the COVID-19 era. Eur Heart J 41(22):2083-2088. https ://doi.org/10.1093/eurheartj/ehaa409

8. Firouzi A, Baay M, Mazayanimonfared A, Pouraliakbar H, Sadeghipour P, Noohi F, Maleki M, Peighambari MM, Kiavar M, Abdi S, Maadani M, Shakerian F, Zahedmehr A, Kiani R, Ansari MJA, Rashidinejad A, Hosseini Z (2020) Effects of the COVID-19 pandemic on the management of patients with ST-elevation myocardial infarction in a tertiary cardiovascular center. Crit Pathw Cardiol. https://doi.org/10.1097/HPC.0000000000000228

9. Tam CF, Cheung KS, Lam S, Wong A, Yung A, Sze M, Lam YM, Chan C, Tsang TC, Tsui M, Tse HF, Siu CW (2020) Impact of coronavirus disease 2019 (COVID-19) outbreak on ST-segment-elevation myocardial infarction care in Hong Kong China. Circ Cardiovasc Qual Outcomes 13(4):e006631. https://doi. org/10.1161/CIRCOUTCOMES.120.006631

10. Tsioufis K, Chrysohoou C, Kariori M, Leontsinis I, Dalakouras I, Papanikolaou A, Charalambus G, Sambatakou H, Siassos G, Panagiotakos D, Tousoulis D (2020) The mystery of "missing" visits in an emergency cardiology department, in the era of COVID-19.; a time-series analysis in a tertiary Greek General Hospital. Clin Res Cardiol. https://doi.org/10.1007/s00392-02001682-1

11. Gluckman TJ, Wilson MA, Chiu ST, Penny BW, Chepuri VB, Waggoner JW, Spinelli KJ (2020) Case rates, treatment approaches, and outcomes in acute myocardial infarction during the coronavirus disease 2019 pandemic. JAMA Cardiol. https:// doi.org/10.1001/jamacardio.2020.3629

12. Katz JN, Sinha SS, Alviar CL, Dudzinski DM, Gage A, Brusca SB, Flanagan MC, Welch T, Geller BJ, Miller PE, Leonardi S, Bohula EA, Price S, Chaudhry SP, Metkus TS, O’Brien CG, Sionis A, Barnett CF, Jentzer JC, Solomon MA, Morrow DA, van Diepen S (2020) Disruptive modifications to cardiac critical care delivery during the Covid-19 pandemic: an international perspective. J Am Coll Cardiol. https://doi.org/10.1016/j. jacc.2020.04.029

13. Shi S, Qin M, Shen B, Cai Y, Liu T, Yang F, Gong W, Liu X, Liang J, Zhao Q, Huang H, Yang B, Huang C (2020) Association of cardiac injury with mortality in hospitalized patients with COVID-19 in Wuhan, China. JAMA Cardiol. https://doi. org/10.1001/jamacardio.2020.0950

14. Chieffo A, Stefanini GG, Price S, Barbato E, Tarantini G, Karam N, Moreno R, Buchanan GL, Gilard M, Halvorsen S, Huber K, James S, Neumann FJ, Mollmann H, Roffi M, Tavazzi G, Mauri Ferre J, Windecker S, Dudek D, Baumbach A (2020) EAPCI position statement on invasive management of acute coronary syndromes during the COVID-19 pandemic. Eur Heart J 41(19):1839-1851. https://doi.org/10.1093/eurheartj/ehaa381
15. Roffi M, Capodanno D, Windecker S, Baumbach A, Dudek D (2020) Impact of the COVID-19 pandemic on interventional cardiology practice: results of the EAPCI survey. EuroIntervention. https://doi.org/10.4244/EIJ-D-20-00528

16. Welt FGP, Shah PB, Aronow HD, Bortnick AE, Henry TD, Sherwood MW, Young MN, Davidson LJ, Kadavath S, Mahmud E, Kirtane AJ, American College of Cardiology's Interventional C, the Society for Cardiovascular A, Interventions (2020) Catheterization laboratory considerations during the coronavirus (COVID19) Pandemic: From the ACC's Interventional Council and SCAI. J Am Coll Cardiol 75(18):2372-2375. https://doi.org/10.1016/j. jacc.2020.03.021

17. De Filippo O, D'Ascenzo F, Angelini F, Bocchino PP, Conrotto F, Saglietto A, Secco GG, Campo G, Gallone G, Verardi R, Gaido L, Iannaccone M, Galvani M, Ugo F, Barbero U, Infantino V, Olivotti L, Mennuni M, Gili S, Infusino F, Vercellino M, Zucchetti O, Casella G, Giammaria M, Boccuzzi G, Tolomeo P, Doronzo B, Senatore G, Grosso Marra W, Rognoni A, Trabattoni D, Franchin L, Borin A, Bruno F, Galluzzo A, Gambino A, Nicolino A, Truffa Giachet A, Sardella G, Fedele F, Monticone S, Montefusco A, Omede P, Pennone M, Patti G, Mancone M, De Ferrari GM (2020) Reduced rate of hospital admissions for ACS during Covid-19 Outbreak in Northern Italy. N Engl J Med. https://doi. org/10.1056/NEJMc2009166

18. Garcia S, Albaghdadi MS, Meraj PM, Schmidt C, Garberich R, Jaffer FA, Dixon S, Rade JJ, Tannenbaum M, Chambers J, Huang PP, Henry TD (2020) Reduction in ST-segment elevation cardiac catheterization laboratory activations in the United States during COVID-19 pandemic. J Am Coll Cardiol 75(22):2871-2872. https ://doi.org/10.1016/j.jacc.2020.04.011

19. Pessoa-Amorim G, Camm CF, Gajendragadkar P, De Maria GL, Arsac C, Laroche C, Zamorano JL, Weidinger F, Achenbach S, Maggioni AP, Gale CP, Poppas A, Casadei B (2020) Admission of patients with STEMI since the outbreak of the COVID-19 pandemic. A survey by the European Society of Cardiology, Eur Heart J Qual Care Clin Outcomes. https://doi.org/10.1093/ehjqc co/qcaa046

20. Albiero RSG (2020) Subacute Left ventricular free wall rupture after delayed STEMI presentation during COVID-19 pandemic: a case report. JACC Case Rep. https://doi.org/10.1016/j.jacca s.2020.06.040

21. Marijon E, Karam N, Jost D, Perrot D, Frattini B, Derkenne C, Sharifzadehgan A, Waldmann V, Beganton F, Narayanan K, Lafont A, Bougouin W, Jouven X (2020) Out-of-hospital cardiac arrest during the COVID-19 pandemic in Paris, France: a population-based, observational study. Lancet Public Health. https:// doi.org/10.1016/S2468-2667(20)30117-1

22. Baldi E, Sechi GM, Mare C, Canevari F, Brancaglione A, Primi R, Klersy C, Palo A, Contri E, Ronchi V, Beretta G, Reali F, Parogni P, Facchin F, Bua D, Rizzi U, Bussi D, Ruggeri S, Oltrona Visconti L, Savastano S, Lombardia CR (2020) Out-of-hospital cardiac arrest during the Covid-19 outbreak in Italy. N Engl J Med. https://doi.org/10.1056/NEJMc2010418

23. Rinkel LA, Prick JCM, Slot RER, Sombroek NMA, Burggraaff J, Groot AE, Emmer BJ, Roos Y, Brouwer MC, van den BergVos RM, Majoie C, Beenen LFM, van de Beek D, Visser MC, van Schaik SM, Coutinho JM (2020) Impact of the COVID-19 outbreak on acute stroke care. J Neurol. https://doi.org/10.1007/ s00415-020-10069-1

24. Nunez JH, Sallent A, Lakhani K, Guerra-Farfan E, Vidal N, Ekhtiari S, Minguell J (2020) Impact of the COVID-19 pandemic on an emergency traumatology service: experience at a tertiary trauma centre in Spain. Injury. https://doi.org/10.1016/j.injur y.2020.05.016 
25. Mohler G, Bertozzi AL, Carter J, Short MB, Sledge D, Tita GE, Uchida CD, Brantingham PJ (2020) Impact of social distancing during COVID-19 pandemic on crime in Los Angeles and Indianapolis. J Crim Justice 68:101692. https://doi.org/10.1016/j.jcrim jus.2020.101692

26. Choudry FA, Hamshere SM, Rathod KS, Akhtar MM, Archbold RA, Guttmann OP, Woldman S, Jain AK, Knight CJ,
Baumbach A, Mathur A, Jones DA (2020) High thrombus burden in patients with COVID-19 presenting with ST-elevation myocardial infarction. J Am Coll Cardiol. https://doi.org/10.1016/j. jacc.2020.07.022 